\title{
"Single coronary" in transposition of the great arteries: Why are we still talking about it?
}

\author{
David L. S. Morales, MD
}

\author{
From the Department of Cardiothoracic Surgery, Cincinnati Children's Hospital Medical Center, Cincinnati, \\ Ohio. \\ Disclosures: Author has nothing to disclose with regard to commercial support. \\ Received for publication March 25, 2016; accepted for publication March 30, 2016; available ahead of print April \\ $28,2016$. \\ Address for reprints: David L. S. Morales, MD, Cincinnati Children's Hospital Medical Center, 3333 Burnet Ave, \\ MLC 2013, Cincinnati, OH 45229 (E-mail: david.morales@ cchmc.org). \\ J Thorac Cardiovasc Surg 2016;152:e33-4 \\ $0022-5223 / \$ 36.00$ \\ Copyright (c) 2016 by The American Association for Thoracic Surgery \\ http://dx.doi.org/10.1016/j.jtcvs.2016.03.059
}

Miyamoto and colleagues ${ }^{1}$ describe an ingenious variation to the already published in situ techniques for single coronary reconstruction in patients with d-transposition of the great arteries (TGA). Their technique attempts to address one of the main long-term issues with the in situ techniques of baffle shrinkage leading to late ischemia. The late fibrosis of artificial material or pericardium was first addressed by the Imai technique by using the nonfacing sinus wall for the baffle. ${ }^{2}$ Miyamoto and colleagues ${ }^{1}$ state that their technique offers a further improvement, in that the baffle instead of being the size of one sinus is half the aortic circumference. This allows coronary unroofing, when required, to not be limited by the size of the baffle. Conversely, a larger baffle may accentuate the other well-described late complication with the in situ techniques: neopulmonary stenosis. With a follow-up period of only 6 months, the impact of this technique on the incidence of these late complications remains unknown. However, the technique is ingenious, and the authors are very careful to state that this is a valuable method in "an inseparable coronary orifice in a single coronary artery when the intramural main coronary artery passes between the great arteries." Why are the authors so specific? Why are there so many techniques for one "entity"? When we tell a colleague that there is a patient with TGA and a "single coronary," do they know what we are telling them?

A "single coronary" in the literature and in practice does not describe a specific entity because many physicians use this term to describe 2 distinctly different entities. The first is a dual coronary system arising from a single aortic sinus via 2 ostia with an incidence of $10 \%$. The second is a coronary system arising from 1 aortic sinus via 1 ostium with an incidence of $5 \% .^{3-5}$ Keeping this in mind, the multiple techniques start categorizing themselves. Most agree that if the coronary system arises from 1 aortic sinus but has 2 orifices, the orifices should be separated and transferred to the neo-aorta with a generous trap door. On the other

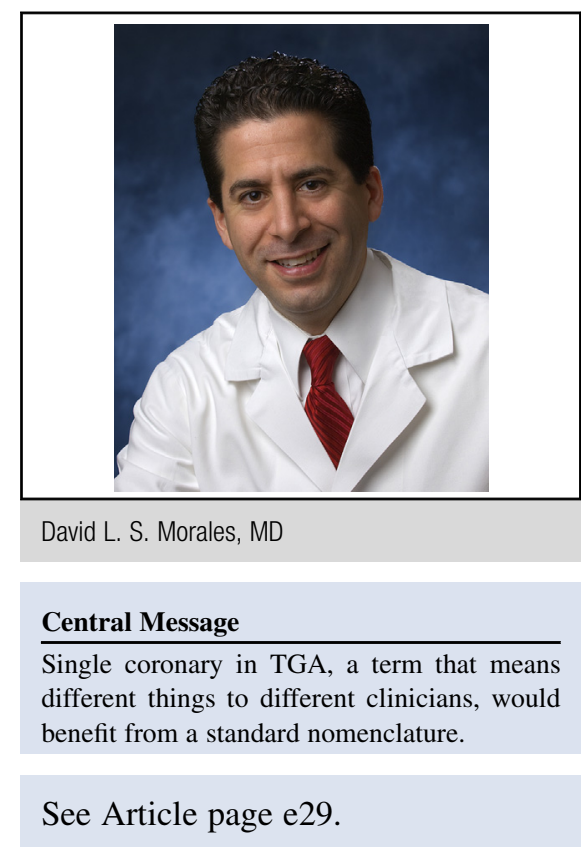

hand, if the 2 orifices are "inseparable," they are effectively 1 orifice and can be grouped in this subcategory of a single ostium. There is an even rarer but well-defined cohort of patients with a single ostium arising from the right facing sinus with the left main traveling between the great vessels. In these patients, the left main is often intramural but not always. It is in these cases when many congenital heart surgeons start to consider in situ techniques for coronary reconstruction. This is where Miyamoto and colleagues ${ }^{1}$ recommend that their technique be applied. If a standard nomenclature could be established to describe single coronary systems arising from 1 aortic sinus in TGA, then the authors would not have had to use 20 words to describe the lesion for which their technique is effective. Also, this would allow the literature on this topic to be more uniform, organized, and directed.

\section{References}

1. Miyamoto T, Yoshitake S, Sasahara A, Naito Y. In situ reconstruction using the half-ring-shaped aortic wall for transposition of the great arteries. J Thorac Cardiovasc Surg. 2016;152:e29-31.

2. Mee RB. The arterial switch operation. In: Stark JF, de Leval MR, eds. Surgery for Congenital Heart Defects. 2nd ed. Philadelphia: WB Saunders Company; 1994: 483-500.

3. Shukla V, Freedom RM, Black MD. Single coronary artery and complete transposition of the great arteries: a technical challenge resolved? Ann Thorac Surg. 2000;69:568-71. 
4. Scheule AM, Jonas RA. Management of transposition of the great arteries with single coronary artery. Semin Thorac Cardiovasc Surg Pediatr Card Surg Annu. 2001;4:34-57.
5. Sung SC, Chang YH, Lee HD, Kim S, Woo JS, Lee YS. Arterial switch operation for the transposition of the great arteries with coronary arteries from a single aortic sinus. Ann Thorac Surg. 2005;80:636-41. 